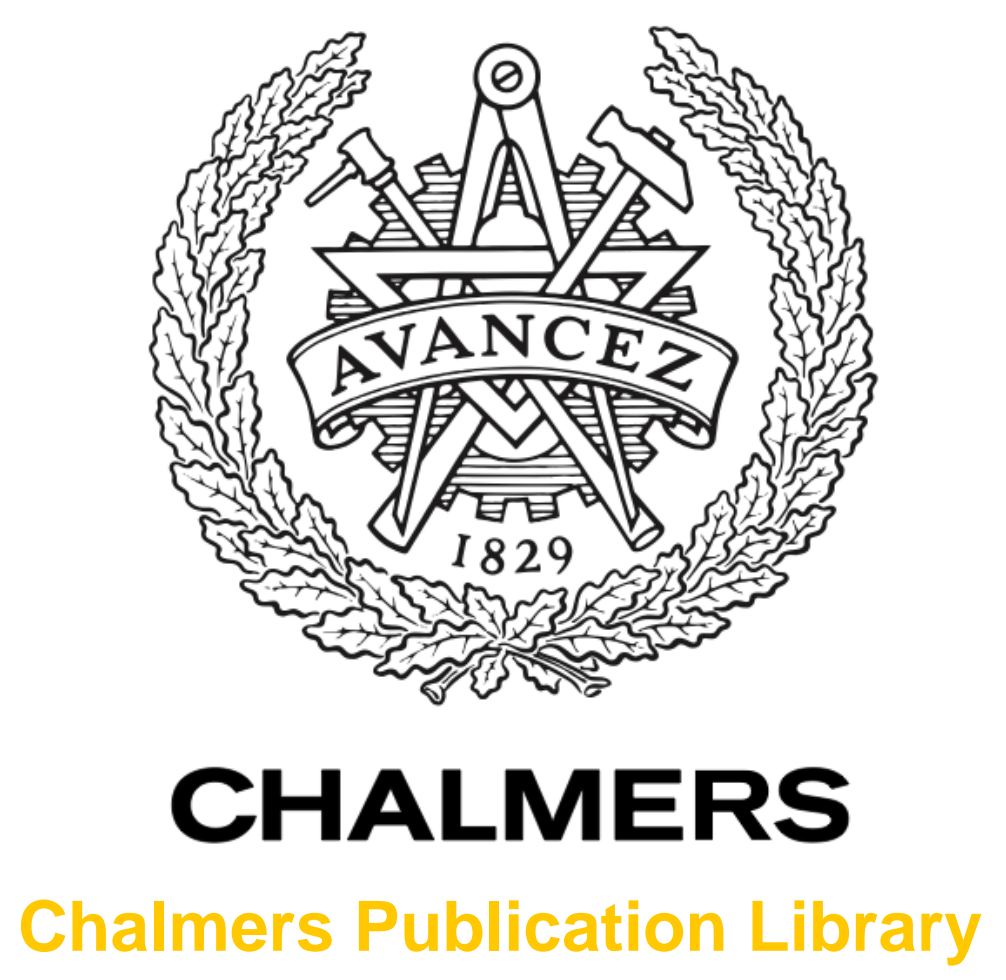

\title{
Estimation of Forest Height and Canopy Density From a Single InSAR Correlation Coefficient
}

This document has been downloaded from Chalmers Publication Library $(\mathrm{CPL})$. It is the author's version of a work that was accepted for publication in:

leee Geoscience and Remote Sensing Letters (ISSN: 1545-598X)

Citation for the published paper:

Soja, M. ; Persson, H. ; Ulander, L. (2015) "Estimation of Forest Height and Canopy Density From a Single InSAR Correlation Coefficient". Ieee Geoscience and Remote Sensing Letters, vol. 12(3), pp. 646-650.

http://dx.doi.org/10.1109/lgrs.2014.2354551

Downloaded from: http://publications.lib.chalmers.se/publication/208868

Notice: Changes introduced as a result of publishing processes such as copy-editing and formatting may not be reflected in this document. For a definitive version of this work, please refer to the published source. Please note that access to the published version might require a subscription. 


\title{
Estimation of Forest Height and Canopy Density From a Single InSAR Correlation Coefficient
}

\author{
Maciej Jerzy Soja, Henrik Persson, and Lars M. H. Ulander, Senior Member, IEEE
}

\begin{abstract}
A two-level model (TLM) is introduced and investigated for the estimation of forest height and canopy density from a single ground-corrected InSAR complex correlation coefficient. The TLM models forest as two scattering levels, namely, ground and vegetation, separated by a distance $\Delta h$ and with area-weighted backscatter ratio $\mu$. The model is evaluated using eight VV-polarized bistatic-interferometric TanDEM-X image pairs acquired in the summers of 2011, 2012, and 2013 over the managed hemi-boreal test site Remningstorp, which is situated in southern Sweden. Ground phase is removed using a highresolution digital terrain model. Inverted TLM parameters for thirty-two 0.5-ha plots of four different types (regular plots, sparse plots, seed trees, and clear-cuts) are studied against reference lidar data. It is concluded that the level distance $\Delta h$ can be used as an estimate of the 50th percentile forest height estimated from lidar (for regular plots: $r>0.95$ and root-mean-square difference $(\sigma)$ $<10 \%$, or $1.8 \mathrm{~m})$. Moreover, the uncorrected area fill factor $\eta_{0}=1 /(1+\mu)$ can be used as an estimate of the vegetation ratio, which is a canopy density estimate defined as the fraction of lidar returns coming from the canopy to all lidar returns (for regular plots: $r>0.59$ and $\sigma \approx 10 \%$, or 0.07 ).
\end{abstract}

Index Terms-Canopy density, forest height, interferometric model, interferometry, synthetic aperture radar (SAR), TanDEM-X, two-level model (TLM).

\section{INTRODUCTION}

$\mathbf{T}$ HERE is a great need for a tool suitable for frequent mapping of large forest areas. Global forest biomass is one of the largest uncertainties in the current climate models [1]. An efficient tool for deforestation detection is needed for the implementation of international agreements [2]. Remote assessment of forest quality is also needed for biodiversity studies and commercial forestry.

Two important forest parameters are forest height and canopy density. In airborne lidar scanning, these parameters are often highly correlated with biomass [3]. Moreover, they can be also used for the assessment of forest quality, as well as deforestation detection.

Manuscript received April 3, 2014; revised August 11, 2014; accepted August 27, 2014. This work was supported by the Swedish National Space Board.

M. J. Soja is with the Department of Earth and Space Sciences, Chalmers University of Technology, SE-412 96 Gothenburg, Sweden (e-mail: maciej. soja@chalmers.se).

L. M. H. Ulander is with the Department of Earth and Space Sciences, Chalmers University of Technology, SE-412 96 Gothenburg, Sweden and also with the Radar Systems Unit, Swedish Defence Research Agency (FOI), SE-581 11 Linköping, Sweden.

H. Persson is with the Department of Forest Resource Management, Swedish University of Agricultural Sciences, 90183 Umeå, Sweden.

Digital Object Identifier 10.1109/LGRS.2014.2354551
Across-track interferometric synthetic aperture radar (InSAR) is a technique in which the scattering center elevation is measured from small phase differences between two SAR acquisitions made at slightly different incidence angles [4]. If a high-resolution digital terrain model (DTM) is available, which is the case in Sweden and many other European countries, the phase introduced by ground topography can be removed, and the remaining phase term is related to the scattering center elevation above ground, which is related to forest height and canopy density [5]. However, the inversion of these parameters from InSAR data is not trivial.

It has been shown that forest height can be estimated from C-, L-, and P-band fully polarimetric InSAR data using random volume over ground (RVoG) model inversion [6]-[8]. For single-polarized InSAR data, simplified versions of the RVoG can also provide estimates of forest height [9]-[11]. The RVoG models forest as a horizontally homogeneous volume, and there is no parameter directly related to the horizontal structure.

In the interferometric water cloud model (IWCM) [12]-[14], the horizontal structure is modeled using canopy gaps. The IWCM has been mainly investigated for stem volume (and later biomass) retrieval, although forest height retrieval has also been studied [15].

The scope of this letter is to introduce a model suitable for the estimation of both forest height and canopy density from a single ground-corrected InSAR complex correlation coefficient. The model is evaluated using single-pass X-band InSAR data acquired with the TanDEM-X twin-satellite system over a hemi-boreal forest in Sweden.

\section{MODELING}

The complex correlation coefficient $\tilde{\gamma}$ is the main observable in an interferometric SAR system. For the two images $s_{1}$ and $s_{2}$, it is defined as

$$
\tilde{\gamma}=\frac{\mathrm{E}\left[s_{1} s_{2}^{*}\right]}{\sqrt{\mathrm{E}\left[\left|s_{1}\right|^{2}\right] \mathrm{E}\left[\left|s_{2}\right|^{2}\right]}}
$$

where $\mathrm{E}[\bullet]$ is the expectation value operator, and ${ }^{*}$ is the complex conjugate operator.

In the case of TanDEM-X InSAR data, the temporal decorrelation over forests is negligible due to the almost simultaneous acquisition scenario [16]. Furthermore, assume that the signalto-noise ratio (SNR) and system decorrelation effects are small, images $s_{1}$ and $s_{2}$ have been filtered to the same 2-D frequency spectrum [17], absolute phase calibration has been applied to remove phase offset, and complex multilooking has been applied to reduce phase and coherence estimation errors (see 


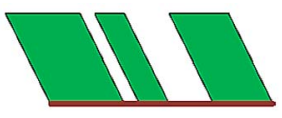

(a) IWCM

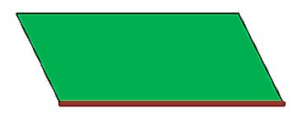

(b) RVoG

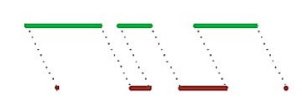

(c) TLM
Fig. 1. Comparison between the different models described in Section II.

Section III-B). In that case, the main decorrelation effect is volume decorrelation, which can be modeled from the vertical backscattering profile $\sigma_{v}(z)$ using

$$
\tilde{\gamma} \approx \tilde{\gamma}_{\mathrm{vol}}=\frac{\int_{-\infty}^{\infty} \sigma(z) e^{j k_{z} z} d z}{\int_{-\infty}^{\infty} \sigma(z) d z}
$$

where $z$ is the vertical coordinate, and $k_{z}$ is the vertical wavenumber, which, for a bistatic system, is

$$
k_{z}=2 \pi B_{\perp} /(\lambda R \sin \theta)
$$

where $B_{\perp}$ is the perpendicular baseline, $\lambda$ is the wavelength, $R$ is the average range to the satellites, and $\theta$ is the average angle of incidence.

\section{A. Vegetation as Random Volume}

A common way to solve the integrals in (2) is through the assumption of a known vertical backscattering profile.

In the IWCM [12]-[14], vegetation is modeled as a volume of randomly oriented scatterers located above a ground plane and covering a certain fraction of the total area, which is called area fill factor [see Fig. 1(a)]. The vertical backscattering profile is then an exponential function described by an attenuation coefficient. The total number of parameters needed for correlation coefficient modeling is five: volume height, ground height, area fill factor, attenuation coefficient, and a ground-tovolume backscatter ratio. Note that, in its full formulation, originally developed for stem volume estimation from repeat-pass ERS-1/2 interferometry [12], [13], the IWCM includes additional empirical functions and temporal decorrelation modeling.

In the RVoG model [6], the gaps modeled by the IWCM are neglected [see Fig. 1(b)], which limits the number of parameters to four. Possible further simplifications used in the past include neglecting the ground component, assuming known ground phase, or fixing extinction coefficient [9]-[11]. The main advantage of the $\mathrm{RVoG}$ is that it requires fewer parameters than the IWCM, but the canopy gaps are not modeled. There is, thus, no natural parameter, which can be used as an estimate for canopy density.

\section{B. Vegetation as Scattering Levels}

A different way to solve the integral in (2) is by simplifying it to a sum of a finite number of discrete scattering levels.

In the special case of two scattering levels, i.e., ground and vegetation, located at $z=z_{0}$ and $z=z_{0}+\Delta h$, with respective backscattering coefficients $\sigma_{\mathrm{gr}}^{0}$ and $\sigma_{\mathrm{veg}}^{0}$, and covering area fractions $1-\eta$ and $\eta$, respectively, (2) simplifies to a two-level model (TLM) [see Fig. 1(c)], i.e.,

$$
\tilde{\gamma}_{\mathrm{TLM}}=e^{i \Phi_{0}}\left(\mu+e^{i k_{z} \Delta h}\right) /(\mu+1)
$$

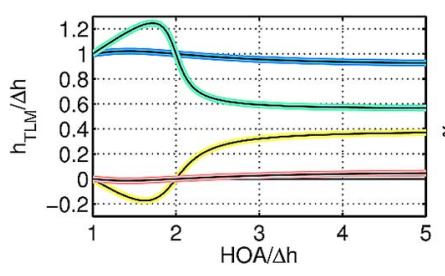

(a) Relative interferometric height

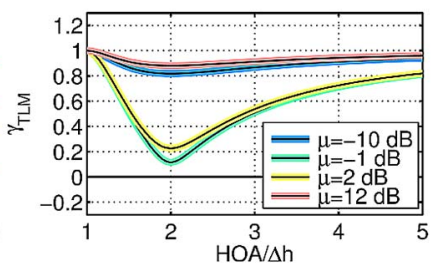

(b) Coherence
Fig. 2. Interferometric height and coherence modeled with TLM.

where $\Phi_{0}=k_{z} z_{0}$ is the ground phase, $\mu=\rho(1-\eta) / \eta$ is the area-weighted (ground-to-vegetation) backscatter ratio, and $\rho=\sigma_{\mathrm{gr}}^{0} / \sigma_{\text {veg }}^{0}$ is the backscatter ratio. In the case of known $\Phi_{0}$, the TLM requires only two independent parameters describing the scene $(\mu$ and $\Delta h)$ to model one ground-corrected complex correlation coefficient, and the inversion can be carried out without any additional data.

\section{Influence of Baseline on Height and Coherence}

Assuming $\Phi_{0}=0$, the interferometric height is computed from the phase of (4) as

$$
h_{\mathrm{TLM}}=\frac{\mathrm{HOA}}{2 \pi}\left[\tan ^{-1}\left(\frac{\sin \left(2 \pi \frac{\Delta h}{\mathrm{HOA}}\right)}{\cos \left(2 \pi \frac{\Delta h}{\mathrm{HOA}}\right)+\mu}\right)+\pi n\right]
$$

where $n$ is an integer describing the phase ambiguity, and $\mathrm{HOA}=2 \pi / k_{z}$ is the height of ambiguity for a bistatic system (maximal height that can be unambiguously resolved by the interferometric system). Likewise, the coherence is computed from the magnitude of (4) as

$$
\gamma_{\mathrm{TLM}}=\left|\tilde{\gamma}_{\mathrm{TLM}}\right|=\frac{\sqrt{1+\mu^{2}+2 \mu \cos \left(2 \pi \frac{\Delta h}{\mathrm{HOA}}\right)}}{1+\mu} .
$$

In Fig. 2(a), the ratio $h_{\mathrm{TLM}} / \Delta h$ is plotted against $\mathrm{HOA} / \Delta h$ for four different values of $\mu$. Phase unwrapping has been performed to ensure continuity and that $0 \leq h_{\mathrm{TLM}} \leq \Delta h$ is satisfied for large HOA. The interferometric height is fairly independent of HOA if scattering at one level is significantly larger than at the other level (large or small $\mu$ ). If $\mu$ is close to unity, scattering at both levels becomes equally significant, and an interference effect is observed for low HOA, i.e., when the phase difference between the two levels is large. In the case of dominant ground-level scattering, negative interferometric heights are obtained. In the case of dominant vegetation-level scattering, interferometric height exceeding $\Delta h$ is observed. In both cases, the interference effect becomes weaker for $\mathrm{HOA}>2 \Delta h$.

Coherence dependence on HOA is illustrated in Fig. 2(b). Coherence is maximized when $\Delta h$ is either close to HOA or much smaller than HOA. In the first case, the phase is similar at both levels during the integration in the numerator of (2) due to constructive interference of two adjacent periods. In the second case, the phase is similar because the phase of $e^{i k_{z} z}$ changes very little between 0 and $\Delta h$, and $e^{i k_{z} z}$ is virtually 
TABLE I

Field Plot Grouping USEd in This Study

\begin{tabular}{|l|l|}
\hline Group: & Description: \\
\hline Regular plots (RP) & $\begin{array}{l}\text { mature, homogeneous, dense plots, no undervege- } \\
\text { tation }\end{array}$ \\
\hline Sparse plots (SP) & $\begin{array}{l}\text { plots with sparse seed trees from past harvesting, } \\
\text { regrown undervegetation and young trees }\end{array}$ \\
\hline Seed trees (ST) & $\begin{array}{l}\text { recently harvested plots with sparse seed trees, no } \\
\text { undervegetation (two in 2013) }\end{array}$ \\
\hline Clear-cuts (CC) & $\begin{array}{l}\text { recently harvested plots, bare soil, no undervegeta- } \\
\text { tion (one in 2012, additional two in 2013) }\end{array}$ \\
\hline
\end{tabular}

TABLE II

Lidar Metrics Used as RefEREnCE IN This Study

\begin{tabular}{|l|l|l|}
\hline Metric: & Property: & Description: \\
\hline \hline $\begin{array}{l}\text { vegetation } \\
\text { ratio (VR) }\end{array}$ & $\begin{array}{l}\text { canopy } \\
\text { density }\end{array}$ & $\begin{array}{l}\text { ratio between lidar returns above } 1 \mathrm{~m} \text { or } 10 \% \\
\text { of maximal height and all lidar returns }\end{array}$ \\
\hline H50 & $\begin{array}{l}\text { forest } \\
\text { height }\end{array}$ & $\begin{array}{l}\text { 50th percentile (median) height for all returns } \\
\text { above } 1 \mathrm{~m} \text { or } 10 \% \text { of maximal height }\end{array}$ \\
\hline H95 & $\begin{array}{l}\text { forest } \\
\text { height }\end{array}$ & $\begin{array}{l}\text { 95th percentile height for all returns above } \\
1 \mathrm{~m} \text { or } 10 \% \text { of maximal height }\end{array}$ \\
\hline
\end{tabular}

constant, giving maximal coherence. Coherence is minimized for $\Delta h=\mathrm{HOA} / 2$, that is, when the interference between the two levels is perfectly destructive. Note that TLM coherence is the same for $\mu$ and its reciprocal $1 / \mu$.

\section{EXPERIMENTAL DATA}

In this letter, data acquired over the boreal test site of Remningstorp (58 $\left.28^{\prime} \mathrm{N}, 13^{\circ} 38^{\prime} \mathrm{E}\right)$, which is situated in southern Sweden, are used. Remningstorp features fairly flat topography with ground height varying between 120 and $145 \mathrm{~m}$ above sea level. The forest consists primarily of Norway spruce, Scots pine, and different birch species. The annual growth rate of the forest is about $10-20 \mathrm{~cm}$, but it is neglected in this study as the study period covers only three growing seasons.

\section{A. Field Plots and Lidar Data}

A set of 32 circular $40-\mathrm{m}$ radius plots is available for Remningstorp. Species-specific field data on biomass, tree number density, and tree height have been used together with field observations, optical SPOT-5 images, and lists with forest management procedures to assess the state of each plot at the time of each SAR acquisition. As a result of these procedures, a time line for the observed changes has been established, and four groups with significant difference in forest structure have been created. These groups are presented in Table I.

Three lidar metrics have been extracted from maps with $10 \mathrm{~m} \times 10 \mathrm{~m}$ pixels provided within the BioSAR $2010 \mathrm{cam}-$ paign [18]. These lidar metric are presented in Table II. As the lidar data have been collected in August 2010, which is before any harvesting procedures have been conducted within the plots, the reference data are not valid for the plots with seed trees and clear-cuts.

\section{B. SAR and DTM Data}

TanDEM-X (TDM) is a twin-satellite X-band $(9.65 \mathrm{GHz})$ SAR interferometer in which acquisitions are made almost simultaneously [16]. Eight bistatic-interferometric VV-polarized
TABLE III

Summary For the TDM Data Used in This Study. Mean VAlues For All Plots Are Given. Background Shading Is by HOA Group

\begin{tabular}{|c|c|ccc|}
\hline Nr: & Date: & $B_{\perp}[\mathrm{m}]:$ & HOA [m]: & Coherence: \\
\hline 1 & 20110604 & 281 & 49 & 0.65 \\
2 & 20110809 & 266 & 52 & 0.66 \\
3 & 20110820 & 257 & 54 & 0.65 \\
\hline 4 & 20120601 & 433 & 32 & 0.73 \\
5 & 20120828 & 371 & 37 & 0.74 \\
\hline 6 & 20130702 & 270 & 51 & 0.66 \\
7 & 20130724 & 226 & 61 & 0.73 \\
8 & 20130804 & 221 & 63 & 0.73 \\
\hline
\end{tabular}

TDM acquisitions made at low HOA in the ascending mode are available and used in this study (see Table III). The nominal incidence angle is within the interval $41.2^{\circ}-41.7^{\circ}$. The data have been divided in three groups according to the approximate HOA level: $35 \mathrm{~m}, 50 \mathrm{~m}$, and $60 \mathrm{~m}$ (images 4 and 5, 1-3 and 6, and 7 and 8 , respectively).

As ground reference, a DTM with a $2 \mathrm{~m} \times 2 \mathrm{~m}$ grid posting and a mean height error lower than $0.5 \mathrm{~m}$ has been used [19]. Four plots are not covered by the two images from August 2011.

TDM data have been interferometrically processed according to [17]. The raw interferograms have been flattened in radar geometry using a linearly interpolated DTM and taking into consideration the quasi-bistatic acquisition geometry and satellite displacement between signal transmission and reception. A 5 - $\mathrm{m}$ buffer zone has been added prior to plot-level averaging of the ground-corrected interferograms. The total number of looks has been estimated to 330 for image 1 (from 2011-06-04) and 430 for the remaining seven images. Absolute phase calibration has been done using ground reference points derived from a nonforest mask. No unwrapping has been found necessary due to the limited height variations in the flattened interferograms. Geocoding error and height measurement errors have been estimated using two 5-m trihedral corner reflectors situated within the test site. The geocoding offset has been found lower than $2 \mathrm{~m}$, and the standard height estimation error has been found lower than $10 \mathrm{~cm}$.

\section{Model InVERsion}

For a fixed $\mu$ and $\Phi_{0}=0$, the TLM is a circle in the complex plane, with its center in $\mu /(1+\mu)$, radius $1 /(1+\mu)$, and passing through unity. Area-weighted backscatter ratio $\mu$ can be obtained from the complex correlation coefficient $\tilde{\gamma}$ as

$$
\mu=\frac{1-|\tilde{\gamma}|^{2}}{1-2 \operatorname{Re}[\tilde{\gamma}]+|\tilde{\gamma}|^{2}}
$$

whereas level distance $\Delta h$ can be found using (7) in (4), i.e.,

$$
\Delta h=\frac{1}{k_{z}}\left[\tan ^{-1}\left(\frac{2 \operatorname{lm}[\tilde{\gamma}](1-\operatorname{Re}[\tilde{\gamma}])}{2 \operatorname{Re}[\tilde{\gamma}](1-\operatorname{Re}[\tilde{\gamma}])-\left(1-|\tilde{\gamma}|^{2}\right)}\right)+\pi n\right]
$$

where $n$ is an integer describing the ambiguity of the inversion; and $\operatorname{Re}[\bullet]$ and $\operatorname{Im}[\bullet]$ are the real and imaginary part operators, respectively. The $2 \pi$-ambiguity can be manually resolved by checking the most probable values in relation to the type of studied forest. For the data used in this study, $n=0$ has been chosen in all cases. 


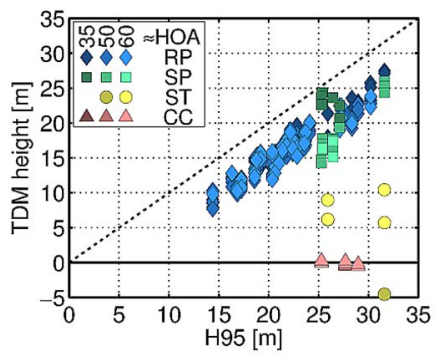

(a) TDM height vs. H95

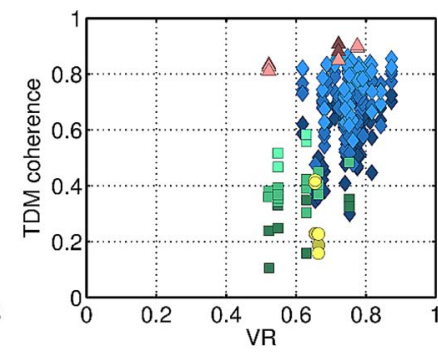

(b) TDM coherence vs. VR
Fig. 3. Scatterplots for TDM observables against lidar reference. Color coding according to plot type has been applied, with different shades for different HOA groups.

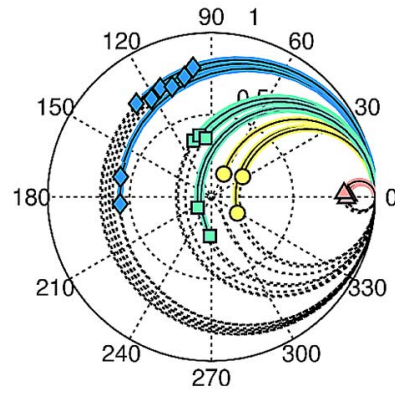

(a) Complex plane

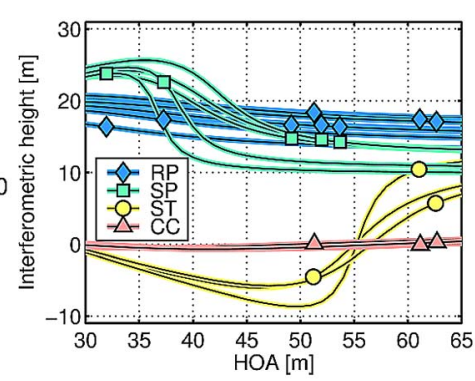

(b) Interferometric height vs. HOA
Fig. 4. Sample fitting results for the different plot types.

If $\mu$ and $\rho$ are known, the area fill factor is $\eta=\rho /(\rho+\mu)$. Normally, the backscatter ratio $\rho$ is not known. Assuming $\rho=$ 1 , i.e., equal ground and canopy backscattering coefficients, the uncorrected area fill factor $\eta_{0}$ can be obtained, i.e.,

$$
\eta_{0}=1 /(1+\mu)
$$

\section{REsults}

TDM interferometric height and coherence are plotted against H95 and VR, respectively, for all eight images and all available plots in Fig. 3. Color coding has been applied for the different plot types and color shading for different HOA groups. A large variance of the interferometric height and a generally lower coherence can be observed for the sparse plots with H95 around $25 \mathrm{~m}$ and for plots with seed trees. This agrees well with the TLM predictions for area-weighted backscatter ratios $\mu$ close to unity (see Fig. 2). Both regular plots and clear-cuts show more predictable behavior with stable height estimates and a higher coherence. Note that the tallest sparse plot is also the densest of all sparse plots, and it shows similar behavior as the regular plots. For the regular plots, the correlation between TDM height and $\mathrm{H} 95$ is high, but an underestimation of 5-10 m is observed. Note also that a large coherence variability is introduced by the differences in the interferometric baseline.

As shown in Fig. 4(a), finding $\Delta h$ and $\mu$ limits to finding a circle in the complex plane. The ratio between the circle center position and its radius is equal to $\mu$. The highest area-weighted backscatter ratio $\mu$ is thus obtained for clear-cuts, and the lowest

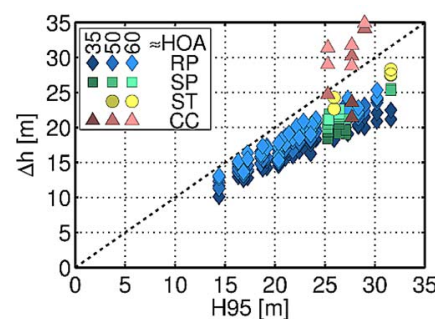

(a) $\Delta h$ vs. $\mathrm{H} 95$

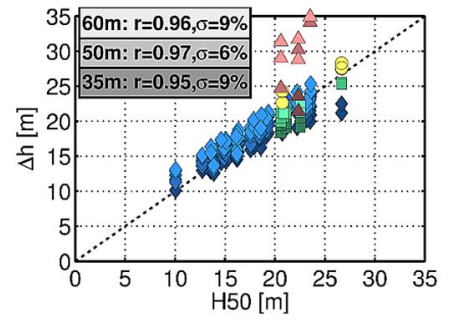

(c) $\Delta h$ vs. $\mathrm{H} 50$

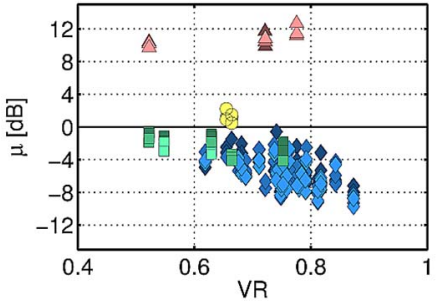

(b) $\mu$ vs. VR

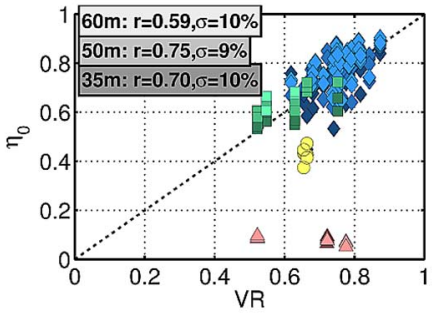

(d) $\eta_{0}$ vs. VR
Fig. 5. Scatterplots for inverted TLM parameters against lidar reference. Pearson correlation coefficients $r$ and root-mean-square differences sigma $(\sigma)$, computed separately for the different HOA groups, are shown for the unaltered plots (both regular and sparse plots)

is obtained for the regular dense plots. In Fig. 4(b), TDM interferometric heights and TLM model curves are plotted against HOA. It can clearly be seen that, in cases when ground- and vegetation-level contributions are comparable, large variance of the interferometric height is to be expected, as in the cases of sparse pine plots and plots with seed trees.

Parameters $\Delta h$ and $\mu$ inverted using (7) and (8) are plotted against H95 and VR in Fig. 5(a) and (b), respectively, for all plots and acquisitions. It is concluded that $\Delta h$ is a biased estimate of $\mathrm{H} 95$, but a better estimate of $\mathrm{H} 50(r \geq 0.96$, and root-mean-square difference $\sigma$ is around $10 \%$ of the mean $\mathrm{H} 50$ ) [see Fig. 5(c)]. Note that there is a HOA-dependent offset between the acquisitions. The area-weighted backscatter ratio $\mu$ does not measure the same property as VR, which is clearly shown in Fig. 5(b). The uncorrected area fill factor $\eta_{0}$ is a better estimate of VR $(r \geq 0.59$ and $\sigma$ around $10 \%$ of the mean VR) [see Fig. 5(d)]. However, a significant variance can be observed.

As observed earlier in Fig. 3(a), plots with seed trees show low and highly variable interferometric heights. In Fig. 5, it can be observed that a harvesting procedure in which sparse seed trees are left does not affect forest height inversion, while the inverted canopy density is lower. For clear-cuts, forest height inversion produces significantly biased results [see Fig. 5(a) and (c)].

Since phase calibration has been done using open fields, the interferometric height for clear-cuts is close to zero, giving an almost real-valued correlation coefficient. However, coherence is between 0.8 and 0.9 , mainly due to SNR and system decorrelation effects. TLM inversion does not provide reliable height estimates because the TLM cannot predict a real-valued correlation coefficient with coherence lower than 1 and low height. This is probably the main cause of the inflated $\Delta h$ estimates for clear-cuts and the HOA-dependent offset. 


\section{DISCUSSION}

The interference effect modeled by the TLM and observed in the data for sparse plots and seed trees occurs when ground- and vegetation-level contributions are similar in strength. Whether this high ground-level contribution at X-band is an effect of dielectric penetration through the scatterers or penetration through canopy gaps has been discussed earlier, most recently in [20], but it is still an open question. The results shown here hint that the inclusion of canopy gaps in modeling is useful, as the inversion provides a parameter that is related to canopy density.

The estimation of canopy density using the uncorrected area fill factor $\eta_{0}$ is based on the assumption that $\rho=1$. Although this assumption appears to be valid for the studied X-band data, the influence of wavelength on $\rho$ is expected to be strong, and the assumption will not hold at other frequencies. If an estimate of the area fill factor $\eta$ is available, e.g., from lidar VR, $\rho$ can be estimated from $\mu$ at scene or plot level and studied against parameters such as weather, season, and ground surface roughness. A better knowledge of $\rho$ can then improve estimation of canopy density from $\mu$.

The TLM in the presented form has been developed for VV-polarized data, and polarization dependence has not been studied. It has been shown in [11] that a difference in the interferometric height can be observed between $\mathrm{HH}$ and VV. Therefore, TLM inversion of $\mathrm{HH}$-polarized data requires a separate study.

This study has been limited to InSAR data with low HOA (smaller than $65 \mathrm{~m}$ ), for which there is a large variation of the interferometric phase between the two levels. However, TLM inversion is expected to work at larger HOA values as well, as long as volume decorrelation is the most significant decorrelation effect.

\section{CONCLUSION}

In this letter, a two-level model (TLM) has been introduced and used for the estimation of forest height and canopy density from bistatic-interferometric VV-polarized TanDEM-X (TDM) data. With an access to the global TDM data, the presented approach can be used on large scale in countries where national high-resolution DTMs exist. Since the DTM is temporally stable in most forested regions, the presented approach requires only one DTM acquisition, and frequent mapping of forest height and canopy density can thereafter be carried out using a spaceborne SAR system such as TDM. The approach is therefore suitable for cost-effective mapping and monitoring of national forest resources. The HOA-dependent height estimation bias observed primarily for open fields and clear-cuts can be avoided through the inclusion of a coherence calibration step during InSAR processing, in which decorrelation effects such as SNR and system decorrelation are compensated for.

\section{ACKNOWLEDGMENT}

The authors would like to thank the German Aerospace Center (DLR) for the TDM data (proposal XTI_VEGE0306); the Swedish Land Survey for the DTM and SPOT-5 data; the
European Space Agency for the BioSAR 2010 lidar data; and G. Eriksen, H. Kjellin, J. Askne, A. Berg, and L. Eriksson for their respective contributions to this work.

\section{REFERENCES}

[1] IPCC Climate Change 2007: The Physical Science Basis. Contribution of Working Group I to the Fourth Assessment Report of the Intergovernmental Panel on Climate Change, Cambridge, U.K.: Cambridge Univ. Press 2007, IPCC.

[2] C. Parker, A. Mitchell, M. Trivedi, and N. Mardas, The Little REDD Book: A Guide to Governmental and Non-Governmental Proposals for Reducing Emissions from Deforestation and Degradation. Oxford, U.K.: Global Canopy Programme, John Krebs Field Station, Nov. 2008.

[3] J. Hyyppä et al., "Review of methods of small-footprint airborne laser scanning for extracting forest inventory data in boreal forests," Int. J. Remote Sens., vol. 29, no. 5, pp. 1339-1366, 2008.

[4] R. Bamler and P. Hartl, "Synthetic aperture radar interferometry," Inverse Problems, vol. 14, no. 4, pp. R1-R54, Aug. 1998.

[5] S. Solberg, R. Astrup, T. Gobakken, E. Naesset, and D. J. Weydahl, "Estimating spruce and pine biomass with interferometric X-band SAR," Remote Sens. Environ., vol. 114, no. 10, pp. 2353-2360, Oct. 2010.

[6] S. R. Cloude and K. P. Papathanassiou, "Polarimetric SAR interferometry," IEEE Trans. Geosci. Remote Sens., vol. 36, no. 5, pp. 1551-1565, Sep. 1998.

[7] K. P. Papathanassiou and S. R. Cloude, "Single-baseline polarimetric SAR interferometry," IEEE Trans. Geosci. Remote Sens., vol. 39, no. 11, pp. 2352-2363, Nov. 2001

[8] F. Garestier, P. C. Dubois-Fernandez, and I. Champion, "Forest height inversion using high-resolution P-band Pol-InSAR data," IEEE Trans. Geosci. Remote Sens., vol. 46, no. 11, pp. 3544-3559, Nov. 2008.

[9] F. Garestier, P. C. Dubois-Fernandez, and K. P. Papathanassiou, "Pine forest height inversion using single-pass X-band PolInSAR data," IEEE Trans. Geosci. Remote Sens., vol. 46, no. 1, pp. 59-68, Jan. 2008.

[10] J. Praks, O. Antropov, and M. T. Hallikainen, "LIDAR-aided SAR interferometry studies in boreal forest: Scattering phase center and extinction coefficient at X- and L-band," IEEE Trans. Geosci. Remote Sens., vol. 50, no. 10 , pp. 3831-3843, Oct. 2012.

[11] F. Kugler, D. Schulze, I. Hajnsek, H. Pretzsch, and K. P. Papathanassiou, "TanDEM-X Pol-InSAR performance for forest height estimation," IEEE Trans. Geosci. Remote Sens., vol. 52, no. 10, pp. 6404-6422, Oct. 2014.

[12] J. I. H. Askne, P. Dammert, L. M. H. Ulander, and G. Smith, "C-band repeat-pass interferometric SAR observations of the forest," IEEE Trans. Geosci. Remote Sens., vol. 35, no. 1, pp. 25-35, Jan. 1997.

[13] J. I. H. Askne, M. Santoro, G. Smith, and J. E. S. Fransson, "Multitemporal repeat-pass SAR interferometry of boreal forests," IEEE Trans. Geosci. Remote Sens., vol. 41, no. 7, pp. 1540-1550, Jul. 2003.

[14] J. I. H. Askne, J. E. S. Fransson, M. Santoro, M. J. Soja, and L. M. H. Ulander, "Model-based biomass estimation of a hemi-boreal forest from multitemporal TanDEM-X acquisitions," Remote Sens., vol. 5, no. 11, pp. 5574-5597, Oct. 2013.

[15] M. Santoro, J. I. H. Askne, and P. Dammert, "Tree height retrieval from ERS interferometric phase in boreal forest," IEEE Trans. Geosci. Remote Sens., vol. 43, no. 2, pp. 207-217, Feb. 2005.

[16] G. Krieger et al., "TanDEM-X: A satellite formation for high-resolution SAR interferometry," IEEE Trans. Geosci. Remote Sens., vol. 45, no. 11, pp. 3317-3341, Nov. 2007

[17] S. Duque, U. Balss, C. Rossi, T. Fritz, and W. Balzer, "TanDEM-X payload ground segment, CoSSC generation and interferometric considerations," Remote Sens. Technol. Inst., German Aerospace Center (DLR), Cologne, Germany, Tech. Rep., 2012.

[18] L. M. H. Ulander et al., "BioSAR 2010: Technical assistance for the development of airborne SAR and geophysical measurements during the BioSAR 2010 experiment: Final report," Eur. Space Agency (ESA), Paris, France, Tech. Rep. Contract No. 4000102285/10/NL/JA/ef, 2011.

[19] "Produktbeskrivning: GSD-Höjddata, grid 2 +," Lantmäteriet, Gävle, Sweden, Tech. Rep., 2013.

[20] F. De Zan, G. Krieger, and P. Lopez-Dekker, "On some spectral properties of TanDEM-X interferograms over forested areas," IEEE Geosci. Remote Sens. Lett., vol. 10, no. 1, pp. 71-75, Jan. 2013. 